DOI: 10.4274/jarem.galenos.2021.3981

J Acad Res Med 2021;11(2):157-63

\title{
Investigation of the Effectiveness of Laser Therapy in Myofascial Pain Syndrome
}

\author{
(1) Nuran Öz1, (이 Nil Sayıner Çağlar2, (1) Nezihe Akar3, (1) Abdullah Akar3, (1) Ebru Aytekin2 \\ ${ }^{1}$ Marmara University Faculty of Medicine, Department of Physical Medicine and Rehabilitation, Division of Rheumatology, İstanbul, Turkey \\ 2University of Health Sciences Turkey, İstanbul Training and Research Hospital, Clinic of Physical Medicine and Rehabilitation, İstanbul, Turkey \\ 3 Yalova State Hospital, Clinic of Physical Medicine and Rehabilitation, Yalova, Turkey
}

Cite this article as: Öz N, Sayıner Çağlar N, Akar N, Akar A, Aytekin E. Investigation of the Effectiveness of Laser Therapy in Myofascial Pain Syndrome. J Acad Res Med 2021;11(2):157-63

\begin{abstract}
Objective: Myofascial pain syndrome (MPS) is a common chronic pain condition affecting the musculoskeletal system and there are various treatment options. In this study, we investigated the efficacy of laser therapy in MPS.

Methods: Sixty patients (35 female, 25 male) diagnosed with MPS due to trigger points in the upper trapezius muscle were included in our study. The patient files were evaluated in two groups of 30 people, each waiting in line with the diagnosis of MPS $(n=30)$ and those who were not yet treated with the same diagnosis $(n=30)$. LED gallium-aluminium-arsenide $1.6 \mathrm{~W}, 808 \mathrm{~nm}$ wavelength diode laser therapy and exercise therapy were applied to the treatment group for 12 minutes once a day for 10 days, while the control group received only exercise therapy. The level of pain at rest and during activity was measured by visual analog scale (VAS); pain intensity and sensitivity was measured by algometric measurement and 0-5 Likert scale; the functional status of the patients was evaluated using the Neck Pain and Disability scale (NPADS) and the quality of life of the patients using the Short Form-36 (SF-36). All these tests were recorded before the treatment, after the treatment and at the $1^{\text {st }}$ month after the treatment in both groups, and the effectiveness of the treatment was examined.

Results: The mean age of the cases was $33.4 \pm 10.5$ in the treatment group and $36.1 \pm 10.6$ in the control group. There was no significant difference between the demographic data of the patients in the control group and laser group. The $15^{\text {th }}$ and $30^{\text {th }}$ day VAS resting scores, VAS activity scores, $0-5$ Likert scale and NPADS scores were found to be significantly lower in the treatment group compared to the control group. Algometric measurement score and SF-36 score on the $15^{\text {th }}$ and $30^{\text {th }}$ days were found to be significantly higher in the treatment group than in the control group.

Conclusion: In this study, it is seen that conventional laser therapy application in the treatment of MPS is effective on pain complaints at rest and during activity, besides, it decreases the trigger point sensitivity and increases the pressure pain threshold on the trigger point.

Keywords: Exercise, laser therapy, myofascial pain syndrome
\end{abstract}

ORCID IDs of the authors: N.Ö. 0000-0002-1002-962X; N.S.Ç. 0000-0002-6882-8686; N.A. 0000-0002-3838-5167; A.A. 0000-0001-6094-4431; E.A. 0000-0002-9619-3374.

Geliş Tarihi/Received Date: 23.11.2020 Kabul Tarihi/Accepted Date: 02.03 .2021 


\section{INTRODUCTION}

Myofascial pain syndrome (MPS), which is a regional pain syndrome, occurs with pain and pain originating from foci in the muscles and/or fascia, called trigger points, as well as referred pain, muscle spasm, tenderness, regional twitching, sensory changes, and sometimes autonomic dysfunctions. MPS is the most common cause of regional pain such as shoulder pain, back pain, tension-type headache and facial pain $(1,2)$. Although it has been suggested that mechanical, nociceptive and geneticpathologies and primary muscle dysfunctions play a role in the pathogenesis of MPS, the exact mechanisms have not been clarified yet (3). There are many treatment methods such as modification of relevant factors, medication, stretching exercises, acupuncture, injections, manual therapy, ultrasound (US), laser therapy, electrical stimulation, transcutaneous electrical nerve stimulation (TENS), acupuncture (4), stretching exercise (5), mesotherapy, massage therapy (6) and biofeedback. These methods are effective in breaking the vicious circle at the trigger point with thermal and/or mechanical effects (7). Recently, some studies have shown that low-level laser therapy may have a therapeutic effect in the treatment of MPS $(8,9)$. The analgesic effect of laser has been shown to stimulate endogenous endorphin synthesis ( $\beta$-endorphin), reduce the activity of $C$ fibers and bradykinin, and change the pain threshold (4). The aim of this study was to evaluate the effects of lowlevel 830-nm gallium-aluminium-arsenide (Ga-Al-As) laser therapy on the treatment of MPS.

\section{METHODS}

This study was planned retrospectively to examine the efficacy of laser therapy in patients diagnosed with MPS based on the diagnostic criteria of Simons et al. (10) in İstanbul Training and Research Hospital Physical Therapy and Rehabilitation Outpatient Clinic. In the study; chronic pain ( $>6$ months), limitation of neck movements, and at least one active trigger point in the trapezius muscle were determined as inclusion criteria, while the presence of neck and/or back pain due to other causes (disc herniation, brachial plexus lesion, degenerative diseases, psychological etc.), previous surgery in the painful area, detection of infection/inflammation, fibromyalgia syndrome (FMS), pregnancy and malignancy history, and abnormal detection of infection parameters were defined as exclusion criteria from the study. Demographic characteristics of the patients, laboratory parameters (biochemistry, erythrocyte sedimentation rate, whole blood analysis, C-reactive protein) and cervical X-rays were examined. All patients were shown a 15-day exercise program and home practice was suggested with posture, active joint range of motion and muscle strengthening (resistance exercises) and stretching exercises for the upper trapezius, levator scapula, scalene, sternocleidomastoid, suboccipital and rhomboid muscles twice a day and 10 repetitions of each exercise. The patients who received laser therapy in addition to exercise therapy constituted the laser group $(n=30)$, and the patients who were recommended exercise therapy but were in the queue for laser therapy constituted the control group $(n=30)$.
Laser treatment with LED Ga-Al-As $808 \mathrm{~nm}$ wavelength and 1.6 Watt power diode laser device (Elettronica Pagani class 1 type BF Italy) for a total of 10 sessions for 12 minutes, 3 joules $/ \mathrm{cm}^{2}$, pulse in $20 \mathrm{sec}$ periods was applied to the painful muscle area at 3,500 Hz with full contact technique and at a right angle (Figure 1).

The patient files were reviewed retrospectively and the efficacy results of the treatment were compared by analyzing the recorded data. Along with the symptoms and signs recorded in the efficacy evaluation files: Visual analog scale (VAS) was used for myofascial pain assessment at rest and activity; algometric measurement and a 0-5 Likert scale to assess pain severity and sensitivity; Neck Pain and Disability scale (NPADS) to assess functional status; Short Form-36 (SF-36) records were used to evaluate quality of life. Pre-treatment, second week and first month post-treatment data, which were used to evaluate the efficacy of treatment in all patients in the treatment and control groups, were collected retrospectively from the recorded files.

\section{Assessment of Pain}

VAS: The meaning of the numbers placed from zero to ten on a $10 \mathrm{~cm}$ line as points: zero as no pain, ten as unbearable pain, and five as moderate pain. After this explanation, the patients were asked to show their pain at rest and during movement on a 10 $\mathrm{cm}$ line (11).

0-5 Likert scale: It is used to determine the severity of pain felt during palpation of the trigger point and is scored between zero and five. 0: Absence of pain, 1: Pain on deep palpation, 2: Pain on superficial palpation, 3: Painful facial expression upon palpation, 4: Jumping with palpation, 5: Avoidance movement with palpation (12).

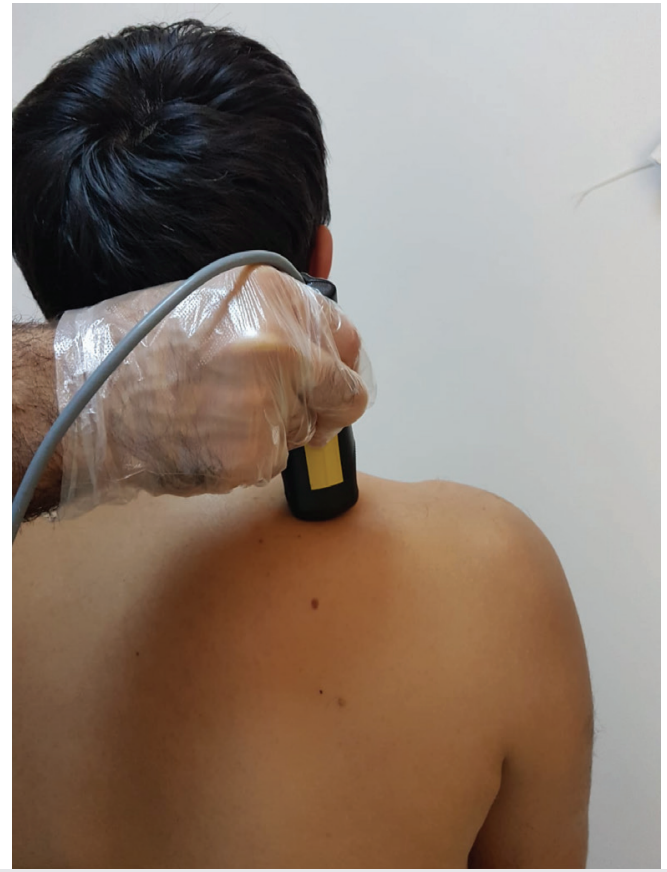

Figure 1. Low-intensity laser application to a patient with myofascial pain syndrome in the upper trapezius muscle 
Algometer (Dolorimeter): Algometer is used to objectively evaluate pain tolerance and pain threshold. Once the trigger point is located, the applied pressure is increased by $1 \mathrm{~kg}$ per second. As soon as the patient first feels the pain, the device is removed from the body surface, while the constant value on the needle is read and the pressure at which the patient feels the pain is recorded as a value of $\mathrm{kg} / \mathrm{cm}^{2}$. The application is repeated three times with an interval of 1 minute and the mean value is recorded as the pressure pain threshold (13).

\section{Functional Status Assessment}

NPADS: NPADS was used to evaluate the disability that occurs in daily life due to neck pain. It consists of 10 items, 4 of which are related to subjective symptoms (pain intensity, concentration, headache, sleep), and 6 of them are related to activities of daily living (personal care, driving, lifting, work life, leisure activities, reading). In NPADS, 0-4 points means no disability, 5-14 points mild disability, 15-24 points moderate disability, 25-34 points severe disability and above 35 points total disability (14).

\section{Quality of Life Assessment}

SF-36 quality of life scale: Consisting of 36 items, it is a criterion used in the evaluation of patients with musculoskeletal complaints. It consists of eight separate parameters. Ten items are used in the assessment of physical function, two items in the assessment of social function, four items in the assessment of role limitations due to physical problems, three items in the assessment of role limitations due to emotional problems, five items in the assessment of mental health, four items in the assessment of vitality, two items in the assessment of pain, five items in the assessment of general health and one item in the assessment of change in health. Both positive and negative aspects of health are questioned. The scores of the items for each parameter are coded and then converted into a scored scale form from zero (worst health condition) to 100 (best health condition) (15).

\section{Statistical Analysis}

Mean, standard deviation, median, frequency and ratio values were used in the statistical evaluation of descriptive data. The distribution of variables was evaluated using the KolmogorovSmirnov test. Independent sample t-test and Mann-Whitney
$U$ test were used in the evaluation of quantitative independent data. The chi-square test was used in the evaluation of qualitative independent data. SPSS 22.0 program was used to evaluate the analyzes. The effect size (Cohen's d) and power value (1- $\beta$ ) of the study were calculated using G*Power software (V.3.1.9.2). The effect size and power value were determined as 2.06 and 0.95 , respectively. A $p<0.05$ level was accepted as statistical alpha significance. Informed consent was obtained from all patients before starting the treatment. Ethics approval was obtained from the İstanbul Training and Research Hospital Clinical Research Ethics Evaluation Committee (decision no: 1001, date: 26.05.2017).

\section{RESULTS}

There was no statistically significant difference between the groups in the age, gender distribution, height, weight and body mass index (BMI) values of the patients in the control group and laser group (Table 1). VAS resting score before treatment, VAS activity score, algometric measurement, 0-5 Likert scale, NPADS, SF-36 mental and physical component score did not differ significantly $(p>0.05)$ in the control group and laser group. In the laser group, VAS resting and activity score, algometric measurement, 0-5 Likert scale, NPADS, SF-36 mental and physical component scores were found to be significantly lower than the control group in the second week and first month after treatment (Table 2). In the laser group, the algometric measurement, SF-36 mental and physical component score at the second week and the first month after treatment were found to be significantly higher than the control group (Table 2).

\section{DISCUSSION}

In this study, pain (VAS, 0-5 Likert scale and algometric measurement), functional status (NPADS) and quality of life (SF36 scale) were evaluated before and after treatment in patients who received laser therapy in addition to exercise therapy for MPS and who did not. There was no statistical difference between laser treatment and control groups in terms of age, gender and $\mathrm{BMI}$ values. There was no difference in pain, functional status and quality of life assessments between the pre-treatment groups, but significant improvements were observed in pain, functional status and quality of life in the $2^{\text {nd }}$ week and $1^{\text {st }}$ month after treatment in the laser treatment group.

\section{Table 1. Demographic characteristics}

\begin{tabular}{|c|c|c|c|c|c|c|}
\hline & & \multicolumn{2}{|c|}{ Control group } & \multicolumn{2}{|c|}{ Laser group } & \multirow[b]{2}{*}{$p$ value } \\
\hline & & Mean \pm SD & Median & Mean \pm SD & Median & \\
\hline \multicolumn{2}{|l|}{ Age (year) } & $36.1 \pm 10.6$ & 35.5 & $33.4 \pm 10.5$ & 30.5 & $0.320^{t}$ \\
\hline Gender & Male & $12(\% 40)$ & - & $13(\% 43.3)$ & - & - \\
\hline Height, m & & $1.70 \pm 0.10$ & 1.7 & $1.69 \pm 0.09$ & 1.7 & $0.463^{m}$ \\
\hline $\mathrm{BMI}, \mathrm{kg} / \mathrm{m}^{2}$ & & $24.0 \pm 2.4$ & 23.7 & $25.0 \pm 4.2$ & 25 & $0.140^{\mathrm{m}}$ \\
\hline
\end{tabular}


MPS is a disease characterized by sensitivity and pain in regional muscles and is the most common cause of local pain such as shoulder pain, back pain, tension-type headache and facial pain. Studies have reported that MPS is detected in approximately $30-50 \%$ of patients who apply to a health institution due to musculoskeletal symptoms $(5,16)$. In two separate studies conducted on patients who applied to the pain outpatient clinic, it was revealed that myofascial pain was the most common cause of pain accompanying $54.6 \%$ of patients with chronic head and neck pain and $85 \%$ of those with back pain (17).

The main focus in the treatment of MPS is the elimination of the trigger point and breaking the loop in the muscles where the "spasm-pain spasm" vicious circle is present. For this reason, various physical therapy methods such as injections applied to the trigger point, low-intensity laser, stretch-spray technique or US, hot pack and TENS can be used. The common effect of these methods disrupts the trigger point with its thermal or mechanical effects and ultimately inactivates it (18). In addition, the effectiveness of exercise on pain is revealed by breaking the vicious circles by reducing facial constraints and muscle tensions, bringing the sarcomere to the optimal length (5). In this study, we aimed to investigate the effectiveness of low-intensity laser therapy in the treatment of MPS, which is very common in the community.
Although myofascial pain and trigger points are predominantly seen in women, they are seen in both sexes. It has been shown in previous studies that it can develop at any age, especially the prevalence of 30-49 years $(5,6)$. In our study, the female sex ratio was found to be $58 \%$ similar to the studies in the literature. The possible reasons for this were thought to be the fact that the majority of patients who applied to our outpatient clinic were women and that female patients remained sedentary in their daily lives. The mean age was 33. The possible reason for this was thought to be the higher prevalence of MPS at these ages and may be related to the inclusion criteria of the study.

Pain is the most important complaint in patients with MPS. For this reason, various scales related to pain are used to evaluate the effectiveness of treatment, and we used VAS, 0-5 Likert scale and algometric measurement parameters in our study. The most commonly used pain assessment scale is VAS $(11,18)$. In a study comparing the efficacy of low-energy laser therapy (LLLT) and pharmacotherapy in patients with temporomandibular disease, it was shown that while a decrease in VAS was observed in the LLLT group, it was not observed in the medical treatment group (19). In a randomized clinical study comparing LLLT with anesthetic lidocaine in patients with orofacial pain diagnosed with FMS, it was found that there was a significant decrease in pain assessed by VAS in both groups, but there was no significant difference

\section{Table 2. Comparison of the VAS, algometric, 0-5 likert scale, NPADS and SF-36 scores}

\begin{tabular}{|c|c|c|c|c|c|c|}
\hline & & \multicolumn{2}{|c|}{ Control group } & \multicolumn{2}{|c|}{ Laser group } & \multirow[b]{2}{*}{$p$ value } \\
\hline & & Mean \pm SD & Median & Mean \pm SD & Median & \\
\hline \multirow{2}{*}{ VAS rest } & Before treatment & $6.4 \pm 1.5$ & 6.5 & $6.1 \pm 1.8$ & 7 & 0.541 \\
\hline & $1^{\text {st }}$ month & $4.9 \pm 1.5$ & 5 & $1.9 \pm 1.4$ & 2 & $<0.001$ \\
\hline VAS activity & Before treatment & $6.8 \pm 1.5$ & 7 & $6.5 \pm 2.1$ & 6.5 & 0.488 \\
\hline \multirow{3}{*}{ Algometric measurement } & Before treatment & $7.2 \pm 1.1$ & 7 & $9.5 \pm 12.4$ & 7.5 & 0.693 \\
\hline & $2^{\text {nd }}$ week & $8.1 \pm 1.1$ & 8 & $11.4 \pm 1.1$ & 11.5 & $<0.001$ \\
\hline & $1^{\text {st }}$ month & $7.9 \pm 1.2$ & 7.8 & $11.4 \pm 1.4$ & 11.5 & $<0.001$ \\
\hline 0-5 Likert scale & Before treatment & $3.6 \pm 0.7$ & 4 & $3.6 \pm 0.6$ & 3.5 & 0.570 \\
\hline \multirow[t]{2}{*}{ NPADS } & $2^{\text {nd }}$ week & $14.6 \pm 5.8$ & 14 & $6.9 \pm 4.5$ & 6 & $<0.001$ \\
\hline & $1^{\text {st }}$ month & $16.4 \pm 5.9$ & 15 & $7.7 \pm 5.7$ & 5.5 & $<0.001$ \\
\hline \multirow{3}{*}{ SF-36 mental component } & Before treatment & $53.1 \pm 17.2$ & 52.5 & $56.6 \pm 18.6$ & 55.9 & 0.487 \\
\hline & $2^{\text {nd }}$ week & $54.0 \pm 16.1$ & 51 & $70.9 \pm 11.4$ & 70.9 & $<0.001$ \\
\hline & $1^{\text {st }}$ month & $52.4 \pm 18.6$ & 51 & $71.4 \pm 11.2$ & 71.4 & $<0.001$ \\
\hline \multirow{3}{*}{ SF-36 physical component } & Before treatment & $59.1 \pm 16.9$ & 61.5 & $61.5 \pm 18.4$ & 59.5 & 0.657 \\
\hline & $2^{\text {nd }}$ week & $60.5 \pm 17.3$ & 60.2 & $77.1 \pm 12.1$ & 78 & $<0.001$ \\
\hline & $1^{\text {st }}$ month & $60.1 \pm 17.4$ & 60 & $77.8 \pm 11.3$ & 78 & $<0.001$ \\
\hline
\end{tabular}


between the groups (20). In our study, activity and resting VAS values were found to be statistically significantly lower in the treatment group for the $2^{\text {nd }}$ week and $1^{\text {st }}$ month. It was observed that these values decreased compared to the baseline values in both groups, but the rate of this decrease was higher in the treatment group than in the control group.

Detection of the trigger point is one of the most important findings with diagnostic value in MPS. Studies have shown that focal tenderness and trigger point of pain are the most reliable physical examination findings $(21,22)$. They are the methods used to determine the trigger point sensitivity via a 0-5 Likert scale and the pressure pain threshold via an algometer $(23,24)$. Pressure pain threshold measurements are frequently used in the evaluation of pain in MPS, cervical region diseases and FMS. The efficacy of the treatment is evaluated with the pressure pain threshold measured using the algometer, from which more reliable numerical and quantitative data are obtained. In a study evaluating the results of VAS, 0-5 Likert scale and algometric measurement parameters, pain and sensitivity at the trigger point decreased statistically in both groups after treatment and 1 month after treatment compared to pre-treatment status, while pressure pain threshold value increased significantly. However, in the mutual evaluation of both groups, improvement was found to be statistically significantly higher in the treated group (18). In a study conducted by Esenyel et al. (25), a statistically significant decrease was found in the 0-5 Likert scale scale and a statistically significant increase in algometer measurements in the groups treated with US and injected compared to the control group. In our study, results similar to previous studies were obtained in the treatment group with a 0-5 Likert scale and an algometer value. Thus, it was possible to evaluate the pain quantitatively. In a study conducted by Delaney and McKee (26), in which the reliability of algometry was investigated in the measurement of trigger point sensitivity, reliable results were found between the measurements of the same and different patients with the algometer in assessing trigger point sensitivity, and it was concluded that it was a convenient method in their follow-up. In our study, it was shown that algometry is a reliable and effective method in the evaluation of response to treatment.

NPADS has been used effectively and safely in many studies in the literature in the clinical follow-up of treatment responses of patients with neck pain and MPS $(27,28)$. It has been shown that the patients in the treatment group were relieved in their functional activities in daily life and this state of well-being continued in the 1-month period after the treatment.

Chronic pain can negatively affect family relationships, work life and social performance of patients with myofascial pain by causing significant difficulties in their daily living activities. Post-treatment SF-36 mental component score and physical component score were found to be significantly higher in the laser group than in the control group. This showed that laser therapy is effective in improving physical and mental functions.

Various studies have shown the effectiveness of low-dose laser therapy in the inactivation of myofascial trigger points and in the treatment of neck pain when applied correctly $(7,19,20,29)$. The aim is to mediate the inflammatory process, regulate physiological cell functions, accelerate the tissue repair process, and provide analgesia in acute or chronic painful conditions (30). When laser therapy is applied to the myofascial trigger point area, it increases local microcirculation, provides oxygen support to hypoxic cells, helps to remove cell metabolic waste products, and breaks the vicious circle between muscle spasm and pain (31). In animal studies, it has been shown that laser therapy decreases intramuscular COX-2 and TNF-alpha levels, and increases beta-endorphin levels in serum, muscle and spinal dorsal root ganglia. In addition, it is thought that laser has a reducing effect on hyperalgesia by decreasing COX-2 mRNA expression in the central nervous system (32). Simunovic (31) showed that HeNe laser therapy was applied to trigger points in different areas and was beneficial, with pain relief, improvement of mobility and reduction of stiffness in myofascial pain. In another study comparing the short-term administration of placebo and LLLT in patients with MPS, laser was found to be effective in reducing pain, improving functional ability and improving quality of life (33). In addition, Altan et al. (34) showed no superiority in a study comparing exercise alone and GaAs laser therapy in the treatment of myofascial pain; however, improvement was observed in both groups. According to the results of another review by Gross et al. (35), including 17 studies published in the literature, 11 of which were chronic myofascial pain; for low-dose laser therapy in trigger point inactivation, treatment parameters with a treatment time of 30-196 seconds, 2-7 days a week, a total of 10 days to 7 weeks have been suggested. In our study, treatment with LED Ga-Al-As laser device was given in accordance with the doses and frequencies recommended in the treatment of chronic myofascial pain in the literature, and we found significant improvements in pain intensity in patients with MPS in one month after the treatment. The features of our study that distinguish it from other laser studies are that no drug treatment is applied, the scope of the exercise program given, the type of laser applied and the application area are different.

\section{Study Limitations}

Our study had the following limitations. First, the limited number of cases included in the study and the fact that it was performed in a single center were the main limitations. Therefore, multicenter studies with large subject groups are needed to confirm our study results. Second, our study was not a placebo-controlled study. Finally, the mean follow-up time of the MPS cases included in the study was relatively short. Longer follow-up studies are required as this period is not sufficient to demonstrate the long-term effects of laser therapy.

\section{CONCLUSION}

We think that the following mechanisms are effective in the inactivation of trigger points in laser therapy: 1) By regulating microcirculation, increasing tissue oxygenation, and normalizing 
the metabolic effects of tissues, 2) by increasing the levels of endogenous opioids and endorphins, affecting the gate control mechanism of pain. To maintain the therapeutic efficacy for a long time, the elimination of the continuation factors present in the patients, provision of posture training, the stretching of the tense and short muscles and the strengthening of the weak muscles are of great importance. On the other hand, there are various studies conducted to determine the optimal dose, duration and frequency of laser therapy to be used in patients with MPS. Further studies with larger patient groups and longer follow-up are needed to determine the optimal dose and duration of treatment, especially since there are no standard guidelines for laser application in terms of duration, frequency, and optimal effective treatment dosages.

Ethics Committee Approval: Ethics approval was obtained from the Istanbul Training and Research Hospital Clinical Research Ethics Evaluation Committee (decision no: 1001, date: 26.05.2017).

Informed Consent: Informed consent was obtained from all patients before starting the treatment.

Peer-review: Externally and internally peer-reviewed.

Author Contributions: Concept - N.Ö., N.S.Ç., A.A.; Design - N.Ö., N.S.Ç., N.A., A.A., E.A.; Data Collection and/or Processing - N.Ö., N.S.Ç., A.A., E.A.; Analysis and/or Interpretation - N.Ö., N.A., E.A.; Literature Search - N.Ö., N.S.Ç., N.A., E.A.; Writing - N.Ö.

Conflict of Interest: The authors have no conflict of interest to declare.

Financial Disclosure: The authors declared that this study has received no financial support.

\section{REFERENCES}

1. Vázquez-Delgado E, Cascos-Romero J, Gay-Escoda C. Myofascial pain syndrome associated with trigger points: a literature review. (I): epidemiology, clinical treatment and etiopathogeny. Med Oral Patol Oral Cir Bucal 2009; 14: e494-8.

2. Hong CZ, Simons DG. Pathophysiologic and electrophysiologic mechanisms of myofascial trigger points. Arch Phys Med Rehabil 1998; 79: 863-72.

3. Grayston R, Czanner G, Elhadd K, Goebel A, Frank B, Üçeyler N, et al. A systematic review and meta-analysis of the prevalence of small fiber pathology in fibromyalgia: Implications for a new paradigm in fibromyalgia etiopathogenesis. Semin Arthritis Rheum 2019; 48: 933-40.

4. Alexander J, Black A. Pain mechanisms and the management of neuropathic pain. Curr Opin Neurol Neurosurg 1992; 5: 228-34.

5. Bron C, de Gast A, Dommerholt J, Stegenga B, Wensing M, Oostendorp RA. Treatment of myofascial trigger points in patients with chronic shoulder pain: a randomized, controlled trial. BMC Med 2011; 9: 8.

6. Moraska AF, Schmiege SJ, Mann JD, Butryn N, Krutsch JP. Responsiveness of Myofascial Trigger Points to Single and Multiple Trigger Point Release Massages: A Randomized, Placebo Controlled Trial. Am J Phys Med Rehabil 2017; 96: 639-45.

7. Hakgüder A, Birtane M, Gürcan S, Kokino S, Turan FN. Efficacy of low level laser therapy in myofascial pain syndrome: an algometric and thermographic evaluation. Lasers Surg Med 2003; 33: 339-43.

8. Munguia FM, Jang J, Salem M, Clark GT, Enciso R. Efficacy of low-level laser therapy in the treatment of temporomandibular myofascial pain: a systematic review and meta-analysis. J Oral Facial Pain Headache 2018; 32: 287-97.

9. Mansourian A, Pourshahidi S, Sadrzadeh-Afshar MS, Ebrahimi H. A comparative study of low-level laser therapy and transcutaneous electrical nerve stimulation as an adjunct to pharmaceutical therapy for myofascial pain dysfunction syndrome: a randomized clinical trial. Front Dent 2019; 16: 256-64.
10. Simons DG, Travell JG, Simons LS. General Overview. In: Johnson EP, editor. Myofascial Pain and Dysfunction: The Trigger Point Manual. 2nd ed. Baltimore: Williams \& Wilkins, 1999: 11-89.

11. Dixon JS, Bird HA. Reproducibility along a $10 \mathrm{~cm}$ vertical visual analogue scale. Ann Rheum Dis 1981; 40: 87-9.

12. Treaster D, Marras WS, Burr D, Sheedy JE, Hart D. Myofascial trigger point development from visual and postural stressors during computer work. J Electromyogr Kinesiol 2006; 16: 115-24.

13. Fischer AA. Documentation of myofascial trigger points. Arch Phys Med Rehabil 1988; 69: 286-91.

14. De Meulemeester KE, Castelein B, Coppieters I, Barbe T, Cools A, Cagnie B. Comparing trigger point dry needling and manual pressure technique for the management of myofascial neck/shoulder pain: a randomized clinical trial. J Manipulative Physiol Ther 2017; 40: 11-20.

15. Çelik D, Çoban Ö. Short Form Health Survey version-2.0 Turkish (SF36v2) is an efficient outcome parameter in musculoskeletal research. Acta Orthop Traumatol Turc 2016; 50: 558-61.

16. Borg-Stein J, Simons DG. Focused review: myofascial pain. Arch Phys Med Rehabil. 2002; 83(3 Suppl 1): S40-7, S48-9.

17. Yunus MB. Research in fibromyalgia and myofascial pain syndromes. Current status, problems and future directions. J. Musculoskeletal Pain 1993; 1: 23-41.

18. Kavadar G, Çağlar N, Özen Ş, Tütün Ş, Demircioğlu D. Efficacy of conventional ultrasound therapy on myofascial pain syndrome: a placebo controlled study. Agri 2015; 27: 190-6.

19. Khalighi HR, Mortazavi H, Mojahedi SM, Azari-Marhabi S, Moradi Abbasabadi F. Low level laser therapy versus pharmacotherapy in improving myofascial pain disorder syndrome. J Lasers Med Sci 2016; 7: 45-50.

20. de Souza RC, de Sousa ET, Scudine KG, Meira UM, de Oliveira E Silva EM, Gomes AC, et al. Low-level laser therapy and anesthetic infiltration for orofacial pain in patients with fibromyalgia: a randomized clinical trial. Med Oral Patol Oral Cir Bucal 2018; 23: e65-71.

21. Nice DA, Riddle DL, Lamb RL, Mayhew TP, Rucker K. Intertester reliability of judgments of the presence of trigger points in patients with low back pain. Arch Phys Med Rehabil 1992; 73: 893-8.

22. Hua NK, Van der Does $E$. The occurrence and inter-rater reliability of myofascial trigger points in the quadratus lumborum and gluteus medius: a prospective study in non-specific low back pain patients and controls in general practice. Pain 1994; 58: 317-23.

23. Jaeger B, Reeves JL. Quantification of changes in myofascial trigger point sensitivity with the pressure algometer following passive stretch. Pain 1986; 27: 203-10.

24. Abu Taleb W, Rehan Youssef A, Saleh A. The effectiveness of manual versus algometer pressure release techniques for treating active myofascial trigger points of the upper trapezius. J Bodyw Mov Ther 2016; 20: 863-9.

25. Esenyel M, Caglar N, Aldemir T. Treatment of myofascial pain. Am J Phys Med Rehabil 2000; 79: 48-52.

26. Delaney GA, McKee AC. Inter- and intra-rater reliability of the pressure threshold meter in measurement of myofascial trigger point sensitivity. Am J Phys Med Rehabil 1993; 72: 136-9.

27. Bicer A, Yazici A, Camdeviren H, Erdogan C. Assessment of pain and disability in patients with chronic neck pain: reliability and construct validity of the Turkish version of the neck pain and disability scale. Disabil Rehabil 2004; 26: 959-62.

28. Ilter L, Dilek B, Batmaz I, Ulu MA, Sariyildiz MA, Nas K, et al. Efficacy of pulsed and continuous therapeutic ultrasound in myofascial pain syndrome: a randomized controlled study. Am J Phys Med Rehabil 2015; 94: 547-5.

29. Kuan TS. Current studies on myofascial pain syndrome. Curr Pain Headache Rep 2009; 13: 365-9.

30. Uemoto L, Nascimento de Azevedo R, Almeida Alfaya T, Nunes Jardim Reis R, Depes de Gouvêa CV, Cavalcanti Garcia MA. Myofascial trigger point therapy: laser therapy and dry needling. Curr Pain Headache Rep 2013; 17: 357.

31. Simunovic Z. Low level laser therapy with trigger points technique: a clinical study on 243 patients. J Clin Laser Med Surg 1996; 14: 163-7.

32. Király M, Bender T, Hodosi K. Comparative study of shockwave therapy and low-level laser therapy effects in patients with myofascial pain syndrome of the trapezius. Rheumatol Int 2018; 38: 2045-52. 
33. Gur A, Sarac AJ, Cevik R, Altindag O, Sarac S. Efficacy of $904 \mathrm{~nm}$ gallium arsenide low level laser therapy in the management of chronic myofascial pain in the neck: a double-blind and randomize-controlled trial. Lasers Surg Med 2004; 35: 229-35.

34. Altan L, Bingöl U, Aykaç M, Yurtkuran M. Investigation of the effect of $\mathrm{GaAs}$ laser therapy on cervical myofascial pain syndrome. Rheumatol Int 2005; 25: 23-7.
35. Gross AR, Dziengo S, Boers O, Goldsmith $\mathrm{CH}$, Graham N, Lilge L, et al. Low Level Laser Therapy (LLLT) for Neck Pain: A Systematic Review and Meta-Regression. Open Orthop J 2013; 7: 396-419. 